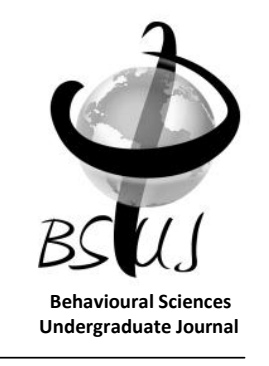

\title{
Understanding Health and Medicine: A Critical Examination of Governance, Surveillance and Control within Contemporary Culture
}

BSUJ 1(1)

http://mrujs.mtroyal.ca/ index.php/bsuj

\author{
Alyssa Hartwella
}

\begin{abstract}
Within contemporary western society, health and medicine understandings are often taken for granted, left unquestioned and undisturbed. However, the author of this paper looks to uproot and critically examine much of what medical professionals, scientists, and patients alike have come to understand as 'normal'. Thus, an assessment of the ways in which the neo-liberal model, the creation of the abnormal/normal binary and social discourses combine in order to enact control, surveillance and governance, will be considered. Then, through the use of Foucauldian theory, a discussion of the implications of such ubiquitous and omnipresent social processes such as surveillance, control and governance will be considered. Furthermore, the neo-liberal model will be presented in greater detail to illustrate the ways in which privilege is cast unto those who embody that of the archetypal citizen. Additionally, social theorists Giddens and Beck will be considered as they offer critical key concepts - such as that of the risk society - which will help to better contextualize the larger theoretical frameworks that exist and pertain to health and medicine. In conclusion, Foucault's concept of the panopticon will exemplify the ways in which surveillance, control and governance are irrevocably intertwined at a variety of levels to ultimately create citizens whom conform to government beliefs and ideals.
\end{abstract}

Key words: abnormal/normal binary, control, Foucauldian analysis, governance, medical discourse, panopticon, surveillance

To date, social theorists and sociologists such as Foucault, Burchell \& Gordon (1991), Foucault (1973, 1979), Giddens (1991) and Beck (1992), have suggested theoretical frameworks and critical concepts to better comprehend the ways in which governance, surveillance and ultimately social control have been constructed throughout time. In turn, such academic infrastructures provide a means of understanding how these ideologies contemporarily operate. In light of these theorists' extensive research and

aMount Royal University

Corresponding Author:

Alyssa Hartwell ahart794@mtroyal.ca 
theoretical perspectives, it is important to critically examine the extensive fabric that intertwines control, surveillance and governance. Together, these concepts render the ways in which health and medicine understandings manifest within contemporary Western society (Beck 1992; Foucault 1979; Giddens 1991; Lupton 2012). It is significant to assess these socially constructed structures at length as they protrude into the organization of everyday life regardless of one's intersectionality ${ }^{1}$. Such social constructions have vast consequences on the experiences and availability of quality health care services for each and every human being living within the western world (Brown 1995; Browne-Yung, Ziersch and Baum 2013; Foucault et al. 1991; Foucault 1979; Lupton 2012; MacLachlan 2006; Nettleton 2006).

The interconnectedness of surveillance, governance and social control, will be studied through discourse analysis. By definition, discourse is an abstract matter that enables signs to assign specific repeatable relations to objects, ideas and subjects (Foucault 1969). Discourse provides a framework of intelligibility and understanding that includes language, action, thought, material life and institutions (Foucault 1969, 1977). Thus, discourse offers meaning and is derived through social interactions and power relations (Foucault 1969, 1977). For instance, within a classroom setting, the professor holds the power to fail students, pass students, give straight A's, eliminate a student's chances of receiving scholarships or ruin one's sense of selfesteem. In this case, the power a professor yields can be understood through the discourse of knowledge.

\footnotetext{
${ }^{1}$ The way one's race, ethnicity, socio-economic status, gender, sex, sexual orientation and the like connect to shape one's unique personal experiences (Parent, DeBlaere and Moradi 2013).
}

By critically examining overarching power structures, the use of Foucauldian power theory will render the ways in which surveillance, governance and control are ubiquitous (Foucault et al. 1991; Foucault 1979; Lupton 2012). Foucauldian power theory states that power is fundamentally linked to wider discourses that are authoritative and is done purposefully and meaningfully through language and thought. Simply defined, ubiquitous means existing or being everywhere at the same time; constantly encountered (Webster's New Collegiate Dictionary 1981). Additionally, it can be argued that Foucault's (1979) panopticon creates the most comprehensive example of the ways in which governance, social control and surveillance intertwine as it qualitatively explains the degree to which the neoliberal model, archetypal citizen, and power relations converge within a medical setting. For Foucault, the panopticon operates as a metaphor for the disciplinary mechanism that regulates and normalizes self-surveillance under the assumption that larger governing bodies and other citizens are watching one's every move (Foucault 1977). For the purposes of this paper, neo-liberalism is best defined as the reiteration of liberal principles that dictates citizens are autonomous actors and that the state should avoid intervention in order to let citizens govern themselves. To elaborate, the archetypal citizen is one whom is "the participatory, autonomous, selfknowledgeable citizen that is privileged in neo-liberalism" (Lupton, 1999, p. 298). Foucauldian theories on matters pertaining to health and medicine are the most pertinent because they endeavour to render the invisible visible by critically analyzing the pervasive structures that have become normalized throughout time and space and no one does this as well as Foucault. It will be argued that health understandings and illness are constructed through the neo-liberal 
model, the creation of the abnormal/normal binary and social discourses in order to enact control, surveillance, and governance at a societal level.

\section{THE HISTORY AND UPRISING OF SURVEILLANCE MEDICINE}

The social discourses that surround the modern understanding of health and illness have largely been constructed within a historical context (Ackerknecht 1967; White K. 2009) and understandings, including the ubiquity of socio-cultural discourses (Foucault 1973; White K. 2009), the abnormal/normal binary (Armstrong 1983; Foucault 1973) and further target specific bodies through surveillance medicine (Fitzpatrick et al. 1984; Foucault 1973). In order to understand the ways in which Surveillance Medicine first came about it is critical to comprehend the historic discourses that underpin its progression throughout time.

Put simply, medicine has changed four times within recorded history - from Library Medicine, to Bedside Medicine, to Hospital Medicine and finally to present day Surveillance Medicine (Armstrong 1983; Foucault 1973; Jewson 1976). Library Medicine pervaded the discourse around health and was understood through doctors' intelligence of health and illness - that is, a time when the learning process of the physician was upheld over any specific information on illness (Armstrong 1995). The practice of Bedside Medicine meant that symptoms could be classified and categorized into specific illnesses that had previously been done without any reason or logic (Armstrong 1995). For example, while once something as simple as a cough or a headache may have incorporated the illness, these signs were later understood as linked to indicate the presence of a larger medical issue. Upon further evolution into Hospital Medicine, practicing physicians had to infer what the symptoms were a sign of in order to finally link them to an illness (Armstrong 1995). Through this understanding, Hospital Medicine meant that the patient's physical body became the focal point of medical attention (Armstrong 1995; Foucault 1973; Jewson 1976).

Ultimately,

widespread

Surveillance Medicine came to rest within contemporary culture. Surveillance Medicine entails the understanding of the symptoms, their significance in relation to larger illnesses and places significant observation on the individual in relation to the larger community (Petersen 1997). This sort of Surveillance Medicine is further enacted through Laboratory Medicine which keeps close watch over an individual's well-being in order to speculate what could transpire in the future (Armstrong 1995; Jewson 1976). Each of these transitions can be understood as an increase in the ubiquity of surveillance and further reinforces a power dynamic through Foucauldian power theory (Foucault 1979; Lupton 2012).

The comprehension of Foucauldian power theory is essential in order to appreciate why health and illness understandings have been constructed through surveillance. Though it must be noted that Foucauldian power theory is a vast and complex subject matter, this framework will be explained as it pertains to health and medicine understandings for the purposes of this paper. Best defined, Foucauldian power theory is a way of comprehending the nature of power relations and the ways in which power is made functional through social control and knowledge (Foucault 1969, 1977, 1979; Lupton 2012; White K. 2009). Further, Foucauldian power theory is fundamentally anchored to discourse and knowledge insofar as discourse produces a system of truth and knowledge that enables forms of power (Foucault 1969, 1977, 1979; Lupton 2012). Thus, Foucault understands power 
as being exuded through an individual's behaviour to a social level where the normative discourse asserts the 'proper action' (Foucault 1969, 1977, 1979; White K. 2009).

Discourse is created through a historical context and displayed through a number of multifaceted ways - the law, media, church, medicine and the government are all included in the same normative discourse (Foucault 1969, $1973,1979)$. There is a particular type of medicine - Surveillance Medicine - that is the most valued way of combating illness within western culture. For example, if a person were to see an herbalist rather than visit a doctor upon getting an infection, this would be considered the 'wrong' way of treating an illness within contemporary western society (MacLachlan 2006). Therefore, there is an idea of the 'right' and 'wrong' way to give aid to the sick (Foucault 1973; MacLachlan 2006). It is significant to note that Foucauldian power theory accounts for individual resistance that may be maintained by challenging the power source of what is right or wrong when one challenges zeself ${ }^{2}$ (Foucault 1977). Resistance is exhibited when one purposefully rejects the discourse with the understanding that there may be consequences for doing so (Foucault 1977). For example, if a person were to intentionally drive through a red light knowing they may receive a ticket, this would be considered resistance.

Upon critically assessing the consequences and repercussions of modern Surveillance Medicine, it becomes apparent that the discourse surrounding one's health is ubiquitous and encompasses the spaces in which one lives. For example, leisure time activities can be critiqued by the luring eyes of the wider community in such a way as to

\footnotetext{
${ }^{2} \mathrm{Ze}$ is a gender-neutral pronoun used to describe men, women, transgendered individuals and the like (Gastil 1990).
}

constantly keep one another in check. The simple indulgence in popcorn at a movie theatre could be assessed as unhealthy and may be further internalized by the individual who has come to understand their own health and wellness through the domination of Surveillance Medicine.

The discourses that saturate Surveillance Medicine have created a normal/abnormal binary thus becoming impossible to attain due to the discourse itself. It must be noted that the abnormal/normal binary within health and medicine understandings is a vast subject matter. Best defined, the abnormal/normal binary is that which has been culturally, historically and communally composed and normalized ${ }^{3}$ as a way of measuring illness such that those who do not fall within the continuum of 'normal' are rendered 'abnormal' and thus 'bad citizens'. Moreover, those who are labelled 'abnormal,' are 'bad citizens', therefore bad citizens exemplify the abnormal. Thus, the abnormal/normal binary is upheld through the neo-liberal model which defines the archetypal citizen, the biomedical model's ${ }^{4}$ division of health and illness, and the normalization process (Armstrong 1995; Ernst 2006). For example, when a child is measured and weighed during medical check-ups, the parents are told their child falls within a certain percentile. This percentile has been accumulated through the abnormal/normal binary in order to render whether the child is 'normal' or

\footnotetext{
${ }^{3}$ This refers to the social creation of ideal behaviours/attitudes based upon binaries and the process of differentiation that constructs binaries (McKinlay and Starkey 1998).

${ }^{4}$ The biomedical model refers to the interconnected system of applied medicine and biological science. This model includes the complex, multidimensional and intricate processes of medicalization which has become increasingly technological and meant to be consumed by individuals and medical companies for treatment and testing of illnesses and diseases (Armstrong 1995; Brown 1995).
} 
'abnormal'. Thereafter, parents are often instructed on how to best insure their child falls within the 'normal' percentile for their age (Armstrong 1995; Lupton 1999). Another example would be if one were diagnosed with diabetes, ze would have to monitor ze's own blood sugars daily by using a glucose meter - in this instance, biomedicine and neo-liberalism provide the framework of what technology is to be used and what is expected of the affected individual. Furthermore, the normalization process works simultaneously through the abnormal/normal binary because normalizing rhetoric and discourse have been used between and amongst medical institutions, patients, and medical professionals to further facilitate the archetypal 'normal' citizen (Nettleton 2006; White K. 2009). Moreover, this notion is best comprehended through Armstrong's (1995) statement, "Surveillance Medicine fixed on these gaps between people to establish that everyone was normal yet no-one was truly healthy" (p. 397). This is significant because through Surveillance Medicine, causal factors such as one's mental, physical, emotional, or even social state could deter one from being qualified as a truly 'healthy' individual (Armstrong 1995; Browne-Yung et al. 2013; Lupton 1999, 2012).

Furthermore, the ways in which surveillance primarily focuses on 'specific bodies' - most notably those who fall outside of the white, heterosexual, male, middle-upper class status - is demonstrated within Lock's (1998) article. ${ }^{5}$ Within her case study, Lock (1998) illustrates the ways in which social discourses and surveillance are internalized through fundamental meanings for women living in Japan and North America during and after

\footnotetext{
${ }^{5}$ Examples of the ways in which surveillance targets particular bodies are available in the sections 'Governance' and 'Neo-Liberalism'.
}

menopause. Lock (1998) explains, “... the female body is the site of contentious debate in connection with both its representation and the medical practices performed upon it" (p. 36). More explicitly, this point of debate over representations and practices upon women's bodies refers to the equity, social autonomy and responsibility women have over their physical bodies. For instance, the debate over whether women should have the right to abort a child should they become pregnant is just one of the many contentious issues around representations and practices upon women's bodies. Furthermore, this is to say that the scientific knowledge and medical practices that surround the female body perpetuate normative expectations through the course of a woman's lifespan. Moreover, Lock (1998) argues that further attention must be paid to the political, moral and epistemological ${ }^{6}$ implications of racialized, gendered, and sexed stereotypes.

Though the observations surrounding women's experiences with menopause and post-menopause differ within North America and Japan, women across borders are made to feel that they are part of a uniform mass (Lock 1998). More specifically, women within North America are socialized to internalize a self-disciplined regimen to ascertain a youthful aesthetic appearance and one's individual biology is given the utmost attention. However within Japan, women are governed $^{7}$ to be responsible for the well-being of the elderly and any amount of physical distress due to a woman's age is likely to be overlooked as a means of

\footnotetext{
${ }^{6}$ The present author argues for an understanding of epistemological implications of sexed, gendered, and racial stereotypes to include an understanding of the origins of sexism, racism and other stereotypes, in order to better comprehend the negative consequences of such attitudes and social constructs.

${ }^{7}$ This sociological concept is defined and discussed at further length in the section titled 'Governance'.
} 
continuing their social tasks (Lock 1998). These cultural spaces and discourses are negotiated through expectations of what a woman's place is within a given society and are shaped through historical and social constraints (Lock 1998; MacLachlan 2006; Nettleton 2006; White K. 2009). Through this understanding of the ways in which social discourses have compounded through surveillance, one might better appreciate how this idea connects to the notion of social control.

\section{SOCIAL CONTROL: RISK \& RESPONSIBILITY}

Within the understandings of health and illness, social control has been utilized and facilitated through two critical components - risk and responsibility (Beck 1992; Foucault et al. 1991; Nettleton 2006; White K. 2009). According to Giddens (1999) a risk society is "a society where we increasingly live on a high technological frontier which absolutely no one completely understands and which generates diversity of possible futures" (p. 3). This is to say that within contemporary society, nothing is certain and extra precautions must be taken in order to minimize any harm that may come to one within everyday life. Responsibility, in this context, refers to the self-reflective, autonomous individual who monitors one's own health and risks in order to promote psychological, social, physical and overall health for oneself and others. The underpinnings of risk and responsibility are further enacted with the social construction of the archetypal citizen and facilitated through the neoliberal model (Beck 1992; Giddens 1991; Foucault et al. 1991; Mol 2008). Neoliberalism, within the context of health and illness, upholds the ideology that citizens are free to exercise their autonomy and emphasizes the entrepreneurial individual who can properly take care of zeself (Beck 1992; Giddens 1991; Mol 2008; Petersen 1997).
Moreover, the ideal citizen must take responsibility to protect zeself from risk. These social constructions and political principles have been enacted through the belief that the 'good citizen' is one that submits to the contemporary health promotion and all that it entails at a community and personal level (Mol 2008; Murdoch, Salter and Cross et al. 2012; Petersen 1997). Those who are included in the category of being an 'at risk' population are generally those who are gendered 8 , ethnic, Aboriginal, and from poor socio-economic backgrounds (Browne-Yung et al. 2013; Nettleton 2006). The idea of attaining health is reified in Petersen's (1997) statement, “ ... 'people's ability to care for themselves, and their access to self-help and social support are recognised as important factors in the achievement and maintenance of good health"' (p.196). The salient discourse that pervades health understandings and illness thus creates a polarization of those who do not have the ability to attain or access the resources needed to attain 'good health' which thus renders them 'bad citizens', and those who do have this ability are rendered 'good citizens' (Beck 1992; Browne-Yung et al. 2013; Giddens 1991; Nettleton 2006; Petersen 1997). In this way, through critical assessment and thought, it becomes increasingly clear how the neo-liberal model facilitates privatization and is enacted through risk, responsibility and ultimately control. Moreover, varying degrees of social control are thrust upon specific bodies ${ }^{9}$ through the risk and responsibility

\footnotetext{
${ }^{8}$ For the purposes of this paper, 'gendered' refers to all people who identify as male, female, transgendered or otherwise. Thus, all gendered entities are understood as being at risk although the degree varies depending upon one's privilege and intersectionality as outlined throughout the duration of this paper (e.g. a white male has more privilege than a white female) (Grekul et al. 2004; Kaw 1991; Salmon 2004; Skloot 2010).

${ }^{9}$ For discussion of these specific bodies, refer to the section titled 'Neo-Liberalism'.
} 
framework (Browne-Yung et al. 2013; Murdoch et al. 2012; Nettleton 2006). Beck (1992) and Giddens (1991) have theorized the understanding of risk as crucial to modern culture and further as upholding the defining features of the self. Beck (1992) illustrates that contemporary society is wrapped up in notions of risk and that individuals are responsible for managing their risk insofar as individuals choose their identity and membership within various groupings (Beck 1992; Nettleton 2006; Petersen 1997). An illustration of the notion of risk would be when patients are asked to get their annual flu vaccine as a means of controlling an outbreak by being responsible citizens for the wider community and personally benefiting as well. This example further renders the ways in which some individuals look to maintain acceptance within the grouping of 'good citizens' whereas those who may not comply with regular vaccines may be labelled 'bad citizens' or 'rebels'.

Previously, risk had been understood as the consequence of an angry omnipresent entity such as that of Mother Nature or God within the PreModern period. For example, if one was eaten by a tiger, it was because Mother Nature was personally upset with that individual (Beck 1992). The understanding of risk then evolved within the Early Modern society and again within Reflexive Modernity. Within the Early Modern society, risk was understood as controllable through political and scientific means among others - for example, tsunami stations are set up to alert residents when there is an impending risk of a tsunami. Finally, Beck (1992) argues that society is currently in a state of Reflexive Modernity whereby citizens are losing faith in overarching social structures such as the government and therefore individualism is emerging. Furthermore, the ruptures between PreModernity, the Early Modern society and Reflexive Modernity have created a sphere in which matters such as unemployment, divorce, or a friendship's termination are seen as a result of one's 'personal failure' (Beck 1992; Petersen 1997). However, Giddens' (1991) comprehension of risk and responsibility dictates that individuals have an array of choices and thus agency. Simultaneously, Giddens (1991) believes that feelings of anxiety and crisis are a normal part of everyday life and that one's shortcomings are a result of their own actions thus one must be held accountable and responsible in doing so. In summary, risk and responsibility are two irrevocably intertwined ideas that pervade the modern understanding of health and illness and are further enshrined through social control.

\section{GOVERNANCE}

Alongside the understanding that control is enacted and reinforced in a plethora of multifaceted ways, governance also serves as a critical piece in the wider comprehension of health and illness. Within this context, governance can be best understood as the ways in which bodies of power institute and facilitate a discourse that privileges particular types of people over others (Brown 1995; Foucault 1979; Lupton 2012; Nettleton 2006). For example, within a doctor's office, a white, upperclass, heterosexual, middle-aged male is more likely to be taken seriously than an Aboriginal, young, female because of the discourse that is perpetuated through governance (Browne-Yung et al. 2013; Foucault et al. 1991; Lupton 1999, 2012; MacLachlan 2006; Nettleton 2006). Furthermore, the consequence of how a young, Aboriginal female is treated with poorer service than that of the white, upper-class, heterosexual, middle-aged male is the very mechanism that maintains governance.

Governmentality is enacted through a compilation of ways including internalizing, educational and social 
means (Brown 1995; Foucault 1979; Lupton 1999, 2012). For instance, within the Australian physical education and health curriculum, children are taught from a young age how to socialize, get along with others, exercise, eat healthily and maintain a superior mental state thus internalizing the archetypal citizen framework as outlined through governance and the neo-liberal model (Lupton 1999). Governance is exemplified and facilitated in Brown's (1995) article, Naming and Framing: The Social Construction of Diagnosis and Illness. Reading Brown's (1995) argument, it becomes abundantly clear that health and illness understandings have been constructed in such a way as to enable a dichotomous relationship that simultaneously relies upon a diagnosis and a label for the medical problem. This black and white division of health and illness understandings is best illustrated through social construction which Brown (1995) discusses as a combination of symbolic interactionism and structuralist/political-economic approaches.

A term originally coined by Herbert Blumer (1969), symbolic interactionism operates under three fundamental premises. First, human beings act towards physical objects, institutions, activities, people and situations on the basis of the meanings that these variables have for them. Second, the meaning of such objects and subjects are derived from or arises out of social interactions between individuals. Finally, symbolic interactionism states that these meanings are given context and modified through one's interpretations of their encounters (Blumer 1969). However, according to Levi-Strauss, structuralism is a theoretical framework that denies any division between "civilized societies" and "primitive societies" (p. 33) but rather states this as an area of study whereby structures are representations of larger social processes to be socially deconstructed (White $\mathrm{H}$. 2009). One illustration of this theory is when young girls are socialized to perform femininity and act 'lady like'. The socialization process of gendered performativity is just one part of the larger social structure of patriarchy.

In its truest form, medical knowledge has been socially constructed as distinct from the social construction of illness (Armstrong 1983; Brown 1995; Lupton 2012; Nettleton 2006; White K. 2009). Medical knowledge has been created through the biomedical framework, the socialization of medical sources (specifically doctors), the institutionalization of the health care system, and moral and ethical value systems (Beck 1992; Brown 1995; Giddens 1991; Mol 2008; Nettleton 2006). In this way, those who possess great power and medical knowledge dictate the overarching framework for those below them within the hierarchy thus discursively distributing a specific type of medical knowledge for others (White K. 2009). This dynamic is further illustrated through the social stratification system that enables a power hierarchy which holds professionals, institutions, the government, media and pharmaceutical companies higher than patients with illness or disease due to one's intersectionality resulting in stigmatization and stereotyping (Lupton 2012; Mol 2008; Nettleton 2006; White K. 2009).

The social construction of health and illness understandings can be seen at the micro level (which enables individuals to be 'good citizens' by monitoring themselves), the meso level (including hospitals and medical knowledge) and the macro level (which facilitates government policies regarding the health care one may receive, as well as political and economic structures) thus rendering its ubiquity (Brown 1995). The centrality of diagnosis is especially pertinent at all levels because not only 
does a diagnosis lie within the confines of a rigid normal/abnormal binary, but further permits a critical assessment over how those within the medical community and within social groups arrive at a diagnosis and who is making it (Brown 1995; Nettleton 2006; White K. 2009; Zola 1966).

As noted by Brown (1995), "Diagnosis locates ... and authorizes medicine to label and deal with people on behalf of the society at large" (p. 39), thus rendering the normalization process due to its acceptance. This is to say that diagnosis is used as a tool for social control through governance. Through a Foucauldian analysis, governance can be understood through a power discourse insofar as knowledge further enables power that resides within the larger governing structures (Foucault 1973; Lupton 2012). In this, Foucault emphasizes the matter of ways in which governmentality enables one to be governed, govern zeself, and how to govern others (Foucault 1973). Moreover, Foucauldian theory would assert that this categorization of illness and diseases through diagnosis operates within the realm of power and constructs power through the discourse itself (Foucault et al. 1991; Foucault 1973; Lupton 2012).

\section{THE NEO-LIBERAL MODEL}

Neo-liberalism is a substantial and extensive concept that has been applied within numerous fields across behavioural sciences and economics indeed some scholars concentrate in this one area alone. However, for the purposes of this paper, the neo-liberal model will be used to illustrate how governance is to be internalized by individuals in order to further indicate how the archetypal citizen is systematically reproduced through the medical model. Furthermore, the neo-liberal model will help to exemplify the ways in which particular bodies are privileged under the neoliberal rule. Best defined, neo-liberalism within the sociology of health and medicine "reinstates liberal principles, including the ideas that citizens are rational, autonomous actors and that the state should avoid excessive intervention into its citizens' affairs and welfare ... we are encouraged to become 'subject to ourselves' ... [through] self-reflection and self-improvement activities that dovetail with governmental objectives as parts of our efforts to achieve individual success and happiness" (Lupton, 1999, p. 289). When it comes to health care, this means that the underlying social structures promote government ideals in that citizens should eat properly, exercise daily, remain in superior mental condition, practise proper self-care and ultimately envelop the archetypal citizen (Lupton 1999; Mol 2008; Murdoch et al. 2012).

The concept of governance's enactment upon health and illness understandings is further exemplified through Lupton's (1999) 'Developing the 'whole me': citizenship, neo-liberalism and the contemporary health and physical education curriculum, in her critical assessment of ideal citizenship, neoliberalism and its enactment through the Australian physical education curriculum. Within her article, Lupton (1999) shares the ways in which schools are a source of reproduction of neo-liberalism in the ideal that the 'good student' is a person who can police, govern and understand zeself. Governmentality becomes the underlying framework which creates laws that are internalized by students at a young age in order to make them easier to govern, which again facilitates the greater neo-liberal model (Foucault et al.1991; Foucault 1979).

Moreover, the expectations placed upon young individuals to be healthy, mindful, social, spiritual citizens, helps to further encompass the government's notions of what it means to truly be 'healthy' and the ways in which this standard is unattainable (Lupton 1999). 
These neo-liberal, nationalist standards of health are irrevocably ethno-centric in nature and thus privilege white, male, heterosexual, upper-class bodies above all else (Browne-Yung et al. 2013; Foucault et al. 1991; Lupton 1999, 2012; MacLachlan 2006; Nettleton 2006). For example, Aboriginal women as well as the 'feeble-minded' have been sterilized without their consent and against their will within Alberta between 1929 and 1972 thus privileging particular male bodies over others (Grekul et al. 2004).

Through Foucauldian power theory, the ways in which governance works through silent discourses in order to discipline individual bodies in the belief that they can become autonomous future citizens becomes prevalent (Foucault 1979; Lupton 1999, 2012; Murdoch et al. 2012). Likewise, Foucault (1979) would argue that the neoliberalist agenda works through students' bodies in order to create docile and productive bodies to systematically reproduce the neo-liberal model (Foucault et al. 1991; Foucault 1979).

\section{EXEMPLIFYING CONTROL, SURVEILLANCE \& GOVERNANCE: FOUCAULT'S PANOPTICON}

Though the processes and enactment of control, surveillance and governance vary in terms of how they operate as outlined throughout this paper, it is important to understand how these concepts are fundamentally interlocked to one another. The salient discourses that encompass these concepts are made indecipherable as a means of normalization within western society's construction of health understandings and illness (Foucault et al. 1991; Foucault 1979; White K. 2009). To further demonstrate how profoundly interlinked these concepts are the notion of Foucault's panopticon will be applied. For Foucault, the panopticon operates as a metaphor for disciplined societies in which surveillance is instilled upon individuals to the point of internalization to bring about self-surveillance (Elliott 2009; Foucault 1979; White K. 2009). Further, surveillance is instilled within citizens in the belief that the government or higher overarching authoritative figures are observing a subject's every move. Therefore, governing ideologies are internalized and thus normalized as people then internally scrutinize themselves to render themselves the archetypal citizen (Foucault 1977, 1979; White K. 2009). For example, if one were to pull up to a stop sign in the early hours of the morning when there is no traffic on the road and ze stops, Foucault (1979) would argue that the panopticon is at work, because there is no one around to police whether ze stops or not, thus the surveillance, control and governance of ze's actions is internalized and further self-policed. The idea of the panopticon further operates through bureaucratic measures such as record keeping and administrative paperwork and is especially prevalent within institutions such as hospitals (Elliott 2009; Foucault et al. 1991; Foucault 1979).

Within the social construction of health and illness understandings the concept of the panopticon can further be explained through a series of stages. First, power and knowledge reside within governance which passes down its ideological discourses - upheld through the neo-liberal model - of what it means to be the archetypal citizen to institutions and structures such as that of science and medicine (Foucault et al. 1991; White K. 2009). Then, the medical construction of health and illness is done through the usage of labels and diagnosis which resides within a power hierarchy in which the government is at the top and is diffused through medical providers to the individual citizens themselves (Foucault 1973, 1979; White K. 2009).

These citizens in general are taught who is 'of risk' (as determined through governance) and ultimately 
patients are made responsible for their own health and risk factors - this is otherwise known as social control (Beck 1992; Foucault 1979; Giddens 1991). Finally, through power discourses enabled by medicine, science, the government and physicians, patients internalize the social discourses of health and illness to be rendered "good citizens" (Foucault et al. 1991; Foucault 1979; White K. 2009).

Additionally, these citizens are meant to embody self-surveillance and simultaneously govern those around them through the power of medical social discourses (Foucault et al. 1991; Foucault 1979; Giddens 1991; White K. 2009). The concept of the panopticon is perhaps the best way to imagine how ubiquitous discourses are created and enacted through control, surveillance and governance (Foucault 1979).

\section{DISCUSSION AND CONCLUSION}

The indications of the above findings are significant insofar as relevant information from social theorists and sociologists such as Foucault et al. (1991), Foucault (1973, 1979), Giddens (1991), and Beck (1992) provide evidentiary support in favour of the ways in which social control, governance and surveillance manifest. Consequently, scientists, medical professionals and patients experiences are shaped through these social constructions. Furthermore, this paper has been able to provide substantial support to shed light upon the ways medical and health understandings are rendered ubiquitous and pervasive for those under the neo-liberal rule (Foucault et al. 1991; Foucault 1979; Lupton 1999, 2012; White K. 2009). Through comprehending the vastness of this overarching discourse and the excess of concepts and ideas encompassed within the discourse, it becomes overwhelmingly clear to see how invasive and detrimental such social constructs can be upon one's overall health.
The future implications of these findings assert that within western culture, citizens must be cautious of the social constructions of social control, governance and surveillance that narrate their very experiences. Regardless of whether one is a medical professional, scientist, patient or otherwise, it is of the utmost importance that we comprehend the vastness and ubiquity of the ways in which the neo-liberal model, the risk and responsibility dichotomy and normative discourse have been integrated into our social world purposefully through power dynamics. While indeed, no one can truly fulfill the archetypal citizen role due to the array of discourses as outlined throughout this paper, certain groups are more susceptible to discrimination based upon their race, ethnicity, gender, sexual orientation or socio-economic status.

As such, there are substantial future concerns for these groups of people. Due to contemporary health understandings, racial women's bodies are taken advantage of and treated as guinea pigs for birth control, sterilization and cell research (Grekul et al. 2004; Salmon 2004; Skloot 2010), racial populations are socially pressured to feel inadequate based on their physical appearance (Kaw 1991), and those who identify as homosexual are still largely misrepresented in light of AIDS research (Treichler 1998). These implications, among others are incredibly problematic and are a result of the neo -liberal model, abnormal/normal binary and risk and responsibility dichotomy (Foucault et al. 1991; Foucault 1973, 1977; Grekul et al. 2004; Lupton 1999, 2012; Salmon 2004; Treichler 1998).

This does not, however, mean that we must understand ourselves as forever perpetuating the discourse that has been created throughout a historical, political, scientific, and medical context. As Foucault (1969, 1973, 1977, 1979) would account, each individual has the ability to resist the discourse by challenging 
ourselves and those around us. By critically analyzing the social structures that encompass contemporary western society, we can challenge the discourse that has become normalized. Furthermore, when citizens come together with the understanding of the ways in which health and medicine discourse has had immeasurable implications for numerous populations, then western culture may make changes within the system for future generations.

\section{Acknowledgements}

I would like to thank Dr. Irene Shankar, Nicole MacInnis, Famira Racy, Dr. Shane Gannon and four anonymous reviewers for their helpful comments, suggestions and support on earlier drafts of this paper.

\section{References}

Ackerknecht, E. 1967. Medicine at the Paris Hospital 1774-1848. Baltimore: John Hopkins. Armstrong, D. 1983. Political Anatomy of the Body: Medical Knowledge in Britain in the Twentieth Century. Cambridge: Cambridge University Press.

Armstrong, D. 1995. The Rise of Surveillance Medicine. Sociology of Health and Illness 17:394-404.

Beck, U. 1992. Risk Society: Towards a New Modernity. London: Sage.

Blumer, H. 1969. Symbolic Interactionism: Perspective and Method. Englewood Cliffs, NJ: PrenticeHall.

Brown, P. 1995. Naming and Framing: The Social Construction of Diagnosis and Illness. Journal of Health and Social Behavior 34-52.

Browne-Yung, K., Ziersch, A., \& Baum, F. 2013. 'Faking til you make it': Social capital accumulation of individuals on low incomes living in contrasting socio-economic neighbourhoods and its implications for health and wellbeing. Social Science \& Medicine 85(C):9-17.

Elliott, A. 2009. Structuralism. Contemporary Social Theory: An Introduction (pp. 70-86). New York: Routledge.

Ernst, W. 2006. Histories of the Normal and the Abnormal: Social and cultural histories of norms and normativity. Taylor \& Francis.

Fitzpatrick, R., Hinton, J., Newman, S., et al. 1984. The Experience of Illness. London: Tavistock.

Foucault, M. 1969. The Archaeology of Knowledge. London and New York: Routledge.

Foucault, M. 1973. The Birth of the Clinic: An Archaeology of Medical Perception. London: Tavistock.

Foucault, M. 1977. Power/Knowledge. New York: Vintage Books.

Foucault, M. 1979. Discipline and Punish. New York: Vintage Books.

Foucault, M., Burchell, G., \& Gordon, C. 1991. The Foucault effect: Studies in governmentality. Chicago: University of Chicago Press.

Gastil, J. 1990. Generic Pronouns and Sexist Language: The Oxymoronic Character of Masculine Generics. Sex Roles 23(11/12):629-643.

Giddens, A. 1991. Modernity and SelfIdentity: Self and Society in the Late Modern Age. Stanford: Stanford University Press.

Giddens, A. $1999 . \quad$ Risk and Responsibility. Modern Law Review 62(1):1-10.

Grekul, J., Krahn, H. and Odnyak, D. 2004. Sterilizing the "Feeble-Minded": Eugenics in Alberta, Canada, 1929-1972. Journal of Historical Sociology, 17(4):358-384.

Jewson, N. 1976. The disappearance of the sick-man from medical cosmologies: $\quad 1770-1870$. Sociology 10:225-244. 
Kaw, Eugenia. 1991. Medicalization and Racial Features: Asian American Women and Cosmetic Surgery. Medical Anthropology Quarterly 7(1):74-89.

Lock, M. 1998. Anomalous Ageing: Managing the Postmenopausal Body. Body \& Society 4:35-61.

Lupton, D. 1999. Developing the 'whole me': citizenship, neo-liberalism and the contemporary health and physical education curriculum. Critical Public Health 9(4):287300.

Lupton, D. 2012. Medicine as Culture: Illness, Disease and the Body. Sage.

MacLachlan, M. 2006. Culture and Health: A Critical Perspective Towards Global Health. John Wiley \& Sons.

McKinlay, A., and Starkey, K. 1998. Managing Foucault: Foucault, Management and Organization Theory.

Mol, A. 2008. The Logic of Care: Health and the Problem of Patient Choice. Routledge.

Murdoch, J., Salter, C., Cross, J., et al. 2012. Resisting medications: moral discourses and performances in illness narratives. Sociology of Health \& Illness.

Nettleton, S. 2006. The Sociology of Health and Illness. Polity.

Parent, M. C., DeBlaere, C., \& Moradi, B. 2013. Approaches to Research on Intersectionality: Perspectives on Gender, LGBT, and Racial/Ethnic Identities. Sex Roles 1-7.

Petersen, A. 1997. Risk, Governance and the New Public Health. The Imperative of Health: Public Health and the Regulated Body (pp. 189206). Sage Publications: London.

Salmon, A. 2004. It takes a community: Constructing Aboriginal Mothers and Children with FAS/FAE as objects of Moral Panic in/through a FAS/FAE Prevention Policy. Journal of the Association for
Research on Mothering 6(1):112123.

Skloot, R. 2010. The Immortal Life of Henrietta Lacks. Random House Digital, Inc.

Treichler, P. 1998. AIDS, Homophobia, and Biomedical Discourse: An Epidemic of Signification. In Culture, Society \& Sexuality (pp. 357-386). Taylor \& Francis Ltd. Books.

Webster's New Collegiate Dictionary. 1981. Ubiquitous.

White, H. 2009. The Content of the Form: Narrative Discourse and Historical Representation. JHU Press.

White, K. 2009. $2^{\text {nd }}$ ed.. An Introduction to the Sociology of Health and Illness. Sage Publications Inc.

Zola, I. K. 1966. Culture and Symptoms: An Analysis of Patients' Presenting Complaints. American Sociological Review 31:615-30. 